\title{
EL ESTADO EN EL PORTUGAL DECIMONÓNICO: EL LIBERALISMO ENTRE EL SUEÑO Y LA RAZÓN (1)
}

\author{
PEDRO TAVARES DE ALMEIDA \\ Universidad Nova de Lisboa \\ tavaresdealmeida@fcsh.unl.pt \\ RUI BRANCO \\ Universidad Nova de Lisboa \\ rbranco@fcsh.unl.pt \\ PAULO SILVEIRA E SOUSA \\ Universidad Nova de Lisboa \\ paulo.sousa@eui.eu
}

(Recepción: 15/05/2015; Revisión: 27/08/2015; Aceptación: 28/12/2015; Publicación: 02/12/2016)

\begin{abstract}
1. El SOBERANO Liberal: MOdelos CONSTITUCIONALES Y REGÍMENES DE SUFRAGIO. 1.1. UNA REVOlUCión Y DOS, O TRES, CONSTITUCIONES. 1.2. El SUFRAGIO. 1.3. ALTERNATIVAS CRÍTICAS: EL NEO-CORPORATIVISMO ORGÁNICO Y EL REPUBLICANISMO CÍVICO.-2. EL ESTADO Y EL TERRITORIO: ENTRE LA CENTRALIZACIÓN Y LA NEGOCIACIÓN. 2.1. El ANTIGUO RÉGIMEN Y LA REVOLUCIÓN. 2.2. El CENTRO Y LAS PERIFERIAS. 2.3. LA CREACIÓN DE UNA ADMINISTRACIÓN NEGOCIADA.-3. EL MERCADO LIBERAL: LA REFORMA DE LOS PESOS Y MEDIDAS. 3.1. «UN REY, UNA LEY, UN PESO Y UNA MEDIDA». 3.2. UNA REFORMA FALLIDA (1814-1851). 3.3. FIAT LUX: LA REFORMA DE 1852.3.4. LA NEGOCIACIÓN COMO MÉTODO DEL REFORMISMO.-4. CONCLUSIÓN.-5. BIBLIOGRAFÍA
\end{abstract}

\section{RESUMEN}

En Portugal el Estado liberal fue el promotor de un proyecto nuevo de comunidad política, de organización del territorio y de la economía, a partir de las experiencias iniciales en 1820-1823. Estableció los principios de la ciudadanía y del sufragio, integró las periferias y estimuló la formación de un mercado nacional. Este artículo analiza cada uno de estos procesos, a partir de la tensión entre la imaginación utópica y su plasmación

(1) Este trabajo ha sido realizado en el marco del proyecto HAR2012-32713 del Plan Nacional de I+D+i. Traducción del portugués al castellano por Juan Pan-Montojo. 
práctica, que frecuentemente suscitó críticas, la formulación de otras propuestas e la creación de procesos de negociación. El imaginario que subyacía a la gobernación liberal no era una tiranía de las fórmulas: en él interactuaban los principios doctrinarios, la agenda política y las prácticas de poder. La construcción del Estado liberal se fundó en un método: la moderación y el compromiso bajo el signo de un reformismo adaptativo. Fruto de estas tensiones las instituciones liberales realmente creadas generaran desencanto y, gradualmente, falta de legitimidad, bien por su cortedad respecto a lo imaginado, bien porque para los más conservadores las nuevas instituciones hubiesen elevado, de forma indefendible, la «rebelión del individuo contra la sociedad», o promovido la presencia de un Estado centralizador y demasiado conformador ante la sociedad y los costumbres de los pueblos.

Palabras clave: Estado liberal; ciudadanía; relaciones centro-periferia; mercado nacional; pesos y medidas; modernización.

\title{
THE STATE IN NINETEENTH CENTURY PORTUGAL: LIBERALISM BETWEEN DREAM AND REASON
}

\begin{abstract}
In Portugal, since the first constitutional experience (1820-1823), the Liberal State was the promoter and builder of a new political project, based on representation, territorial reform and economic reorganization and standardisation. Its power apparatuses established the principles of citizenship and suffrage, integrated the peripheries and shaped a new national economic space. Stressing the tension between utopian political imagination and pragmatic processes, this article analyses each of these three main changes, which often faced strong debate, adjustments and the creation of forms of negotiation between the central administration and local political networks and agents. The imaginary that was behind liberal governance was not a tyranny of concepts; it combined doctrinal principles, political agendas and practices of power. The construction of the Portuguese Liberal State was hence based on moderation and compromise under an adaptive reformism guided by oligarchic networks. These tensions influenced the liberal institutions that were actually created and generated disenchantment, and gradually, affected the regime's legitimacy. For Progressives, new institutions stayed short in relation to their political imagination; for Conservatives they had raised too high the «rebellion of the individual against society» and overdeveloped centralisation and the subordination of society and customs of the peoples to the State.
\end{abstract}

Keywords: Liberal State; citizenship; centre-periphery relations; national market; weights and measures; modernisation.

$$
* \quad * \quad *
$$

El liberalismo llegó como utopía de transformación y de gobierno de una sociedad que los liberales imaginaban infinitamente dúctil y, al mismo tiempo, 
renitente. Esta paradoja fue expresada de forma diáfana por el liberal Don Pedro, en 1832, al desembarcar en Oporto en plena Guerra Civil, cuando exhortó a la población a abandonar «al Usurpador [el absolutista don Miguel, su herma-

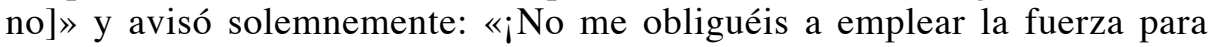
liberaros!» (2). Pese al sueño voluntarista de los liberales, la Guerra Civil duró todavía dos largos años más. Victoriosos en el terreno militar, sus programas de reforma siguieron, casi siempre, una vía doctrinaria moderada, pero sin concesiones al antiguo campo absolutista.

El Estado liberal fue el gran promotor de un proyecto nuevo de comunidad política, de organización del territorio y de la economía desde las experiencias iniciales en 1820-1823. Estableció los principios de la ciudadanía, integró las periferias y estimuló la formación de un mercado nacional. Este trabajo analiza y problematiza cada uno de estos procesos, a partir de la tensión entre la imaginación utópica y su plasmación práctica, que frecuentemente suscitó críticas y la formulación de otras propuestas.

La primera sección se centra en la cuestión de la ciudadanía y la representación. ¿En qué términos debía participar el nuevo soberano, el pueblo, en la política y en el gobierno de sí mismo? La respuesta fue el sufragio censitario y por capacidades. A la vez nacional, individualista y anti-corporativo, el sufragio liberal consiste en una construcción social del electorado como comunidad política imaginada. Las leyes electorales tenían un objetivo normativo y un efecto performativo: corporizaron y otorgaron sentido al individuo soberano en el cuadro del Estado-nación moderno. Esta construcción atrajo dos tipos principales de críticas: las que proponían como opción contrapuesta categorías orgánicas o neo-corporativas y las que buscaban llevar el principio de igualdad política a su corolario lógico, la república democrática.

La segunda sección analiza las transformaciones del Estado y del territorio. La victoria de los liberales en la Guerra Civil condujo a la separación de los poderes, racionalizó los instrumentos de administración y reforzó la tutela sobre las instituciones locales. En la administración territorial, Portugal adoptó una versión del modelo napoleónico y la reformó en sucesivas ocasiones a lo largo del siglo XIX, casi siempre en un sentido considerado demasiado centralizador. Sin embargo, un examen atento de las reformas liberales revela que estas percepciones subestiman la importancia de los procesos de negociación entre el centro y las periferias. Por detrás de la retórica de la centralización se esconden redes de influencia y de notables locales, en un Leviatán que era mucho menos poderoso y autosuficiente.

Finalmente, estudiaremos la reforma de los pesos y medidas, con la introducción del sistema métrico-decimal. En pocos aspectos del reformismo liberal se pone tan en evidencia la extinción de los particularismos propios del Antiguo Régimen. Por un lado, el nuevo sistema venía a sustituir una multitud de

(2) Anónimo (1840): 54. 
«mundos» locales, que traducían otros tantos sistemas de pesos y medidas, por una única medida que reflejara una única nación. Por otro, resultaba la condición de posibilidad del mercado nacional y de una economía moderna. Por último, se entendía que venía a desequilibrar a favor del centro gubernamental la distribución de poder en la comunidad política, ocupando en la imaginación liberal el lugar de una discreta «madre de todas as revoluciones» (3)

\section{EL SOBERANO LIBERAL: MODELOS CONSTITUCIONALES Y REGÍMENES DE SUFRAGIO}

\subsection{Una revolución y dos, o tres, constituciones}

La revolución de 1820 inauguró el siglo en el que el pueblo fue incorporado al espacio de la soberanía y en el que la polity se imaginaba de modo esencialmente diferente. Las revoluciones francesa y norteamericana constituyen los lugares clásicos de esa mudanza, que tuvo curso pleno en las revoluciones ibéricas de 1820, así como en las de la América Latina de la primera mitad del ochocientos.

El contrato social liberal colocaba al pueblo, o a la nación, «en el lugar divino y como propietario de una soberanía autosuficiente», modificando así las reglas de la representación política: la unidad representada pasaba a ser el individuo, a través de asambleas nacionales electivas, y no la familia, la propiedad o la corporación, a través de cuerpos funcionales separados (Stände, la palabra alemana para estamentos) (4). Si bien ese contrato social implicaba la destrucción de la arquitectura corporativa y policéntrica del Antiguo Régimen, el proceso que pretendía desembocar en él, en sus múltiples variantes históricas, se tradujo en muchos aspectos en un compromiso y permitió diferentes continuidades (5).

En cualquier caso, las formas liberales de representación consagraron las desigualdades entre los individuos en el plano político, fracturando la ciudadanía. La representación fue confiada a los más acomodados y a los más instruidos, los únicos capaces de tomar decisiones racionales sobre los negocios públicos. Por eso, sus instituciones vivieron en tensión permanente con el núcleo igualitario del paradigma post-revolucionario, dando lugar a críticas y alimentando la construcción de modelos alternativos. Este juego de tensiones se expresó en dos ámbitos principales: el modelo constitucional y la regulación del sufragio.

(3) ORDONEZ (2008): 53.

(4) CATROGa (2010): 24.

(5) Tavares de Almeida (1991): 15-18. 
La monarquía constitucional portuguesa dio estabilidad a una fórmula moderada, fundada en la Carta otorgada en 1826. A esa estabilidad se llegó tras una dura contestación y tras diferentes enmiendas. La primera resistencia partió de los partidarios de la restauración absolutista, defensores de la «constitución tradicional del reino» (6). Derrotados estos en la Guerra Civil, se alzó la contestación de los sectores avanzados que, en el curso de una insurrección revolucionaria (1836), impusieron la restauración de la Constitución vintista, sustituida poco después por una tercera constitución (1838). Restaurada en 1842, después de un golpe de estado conservador, la Carta solo se convirtió en un documento de consenso tras su revisión por el Acta Adicional de 1852.

La Constitución de 1822, inspirada en la de Cádiz (7), se basaba en el principio representativo democrático: la soberanía residía en la «nación» y era ejercida en las Cortes por los representantes elegidos. La monarquía se hallaba limitada por la soberanía nacional y por la separación de poderes: recaía el legislativo en la asamblea unicameral (las Cortes); el ejecutivo, en el rey y los secretarios de Estado; el judicial, en los tribunales. El papel del rey era secundario, nacía de una autoridad derivada y tenía competencias limitadas (no podía disolver las Cortes y su poder de veto únicamente era suspensivo). Al contrario del texto español, el portugués aceptaba el sufragio directo sin restricciones censitarias, si bien excluía -además de a las mujeres- a los menores de 25 años, a las personas dependientes, a los eclesiásticos regulares y, con vistas al futuro, a los analfabetos.

Independientemente de que se viese en la Constitución un texto puramente radical, «una república disfrazada de monarquía» (8), o el producto de circunstancias inciertas, sobre las que habrían resultado determinantes la influencia de la revolución española y la ausencia del rey que se hallaba en Brasil (9), es cierto que la Constitución vintista abrigaba una visión utópica indiscutible, especialmente si tenemos en cuenta el contexto contrarrevolucionario que prevalecía en esos momentos en Europa. La ley fundamental de 1822 alteraba profundamente la idea de monarquía, contraponiendo al régimen absoluto un régimen constitucional representativo, de fuerte sesgo parlamentario, situado en el campo avanzado del liberalismo. Y por ello suscitó la oposición de los defensores del orden absolutista y a la vez dividió el campo liberal, dando lugar a la oposición de los más moderados. Y es que al igual que en España la Constitución de Cádiz parecía inaplicable a los moderados, la Constitución vintista parecía ofrecer una base estrecha, por demasiado radical, para consolidar el régimen liberal. La cuestión crucial para el liberalismo moderado ibérico era contar con una constitución realizable, que estableciese la libertad con orden.

(6) FerReira da Costa (1828) cit. in Hespanha (2004): 153-159.

(7) Una comparación entre los modelos constitucionales ibéricos en SUANZES-CARPEGNA (2007).

(8) Bonifácio (2005): 26, siguiendo a Oliveira Martins (1991 [1879]): 404-408.

(9) MONTEIRo (2013): 59-60. 
Por el contrario para los liberales avanzados, la constitución tenía que conciliar la libertad con una amplia representación popular y suponer una ruptura profunda con la organización política, los grupos de poder y las estructuras de administración del Antiguo Régimen.

En 1826, Pedro IV otorgó una Carta Constitucional moderada. En su articulado el poder constituyente nacía del principio monárquico, si bien tamizado por el representativo, puesto que consideraba representantes de la Nación al rey y a las Cortes: al hacerlo, excluía el principio de la soberanía nacional. La Carta recogía la división de poderes, pero introducía el poder moderador y consagraba la división entre ciudadanos activos y pasivos. El poder legislativo quedaba atribuido a las Cortes, formadas por la Cámara de los Diputados, elegida por sufragio indirecto censitario, y por la Cámara de los Pares, de nombramiento real, hereditaria y vitalicia. El poder ejecutivo correspondía al monarca y a los ministros; el judicial, a los tribunales. El rey ejercía el poder moderador, con la facultad de sanción de las leyes y con veto absoluto, además de poder convocar y suspender las Cortes, disolver la Cámara de los Diputados, nombrar y destituir a los ministros y designar pares. La conversión del monarca en árbitro del proceso político suponía colocar al parlamento en una posición subalterna. El sufragio directo y casi universal de 1822 cedió paso a un sufragio censitario restringido de tipo indirecto y se diferenció y jerarquizó el cuerpo electoral, estableciéndose requisitos exigentes para ser elegido diputado.

La Carta de 1826 no pretendía ser la antítesis do texto vintista; trataba de ensanchar la coalición de fuerzas sociales y políticas favorables al liberalismo. $\mathrm{Su}$ legislador «no recuerda, ni inventa»: no anhela la ciudad ideal sino que trabaja «sobre lo concreto de estados constituidos y existentes, heredando del pasado un territorio, una población» (10). En ese sentido, el texto de la Carta es más maleable y menos prescriptivo que el de la Constitución de 1822. Como idea de sociedad y de política, el cartismo ocupó el espacio entre el «derecho divino de los reyes y la plena soberanía de los pueblos»; criticó el tradicionalismo pleno y el radicalismo revolucionario; concedió al vocabulario político liberal sentidos específicos -la legitimidad como permanencia y continuidad por oposición a la volubilidad constituyente; la representación como «capacidad y 'razón pública' jerarquizadora y oligárquica contra la voluntad pactista horizontal e igualitaria» (11).

La Constitución de 1838, inspirada en la ley fundamental española de 1837 y en la belga de 1831, trazó una línea intermedia entre la Constitución vintista y la Carta, aunque se encontrase más cerca de la primera: reafirmaba la soberanía nacional, recuperaba el sufragio directo, redujo el censo electoral en lo tocante a electores pero no a elegibles y eliminó el poder moderador, aunque instituyese una Cámara de Senadores, elegida por sufragio directo censitario cada seis

(10) HesPanha (2004): 163-165, 365-367.

(11) SARDICA (2012): 529. 
años. El texto de 1838 era el resultado de un primer compromiso cauteloso. Apartado de las soluciones radicales de los sectores democráticos, plasma las corrientes románticas, historicistas y «doctrinarias», más próximas el cartismo, tan bien representadas en intelectuales-políticos como Mouzinho da Silveira, Almeida Garrett o Alexandre Herculano. En efecto, en la opinión de este último, la Constitución de 1838 «era un campo neutral donde todos se podían encontrar pacíficamente y buscar, sin salir de la legalidad, el predominio de sus respectivas opiniones» (12).

No obstante, tal cosa no ocurrió, en buena medida por la reacción conservadora y por el apoyo que esta obtuvo por parte de la reina María II y de sectores mayoritarios del Ejército. La querella constitucional entre las corrientes políticas del régimen únicamente se terminó tras el golpe militar de la Regeneração en 1851, que permitió que se diesen las condiciones políticas para el compromiso plasmado en la revisión de la Carta a través del Acta Adicional de 1852. Esta reforma atendió a reivindicaciones históricas de los sectores más progresistas: sufragio directo y moderación de los requisitos censitarios, aprobación parlamentaria de tratados, votación anual de los impuestos y derogación de la pena de muerte para delitos políticos. A cambio, y con la expectativa de acceder al gobierno de forma regular y constitucional, los progresistas aceptaron la Carta -y por lo tanto lo que suponía de rechazo de los principios de soberanía popular y democracia-. El Acta Adicional era un pacto para superar el conflicto endémico dentro de las élites liberales. Permitió abrir un periodo de consolidación del liberalismo, con una relativa estabilidad fundada en la dinámica del rotativismo (turnismo), sobre todo a partir de 1878 (13).

\subsection{El sufragio}

El sufragio censitario restringido consignado en la Carta expresaba la visión del doctrinarismo en relación al «electorado-función», según la cual el sufragio no era un derecho innato ni se podía adquirir a través de procesos revolucionarios, por lo que esencialmente no podía ser universal. El sufragio constituía una distinción a la que se accedía por la posesión de independencia económica y de capacidad intelectual. Permitía deliberar racionalmente en nombre del interés público, liberado de las amarras de la heteronomía, la irracionalidad y la ignorancia (14). Era esto lo que Herculano quería decir cuando declaraba que si las leyes «se guiasen por los principios eternos de lo bueno y de lo justo, $[\ldots]$

(12) HerCULANO (1897 [1873]): 28-29.

(13) La Carta fue revisada más veces: en 1885, 1895-1896 y 1907. Vid. FERnANDES (2012): 569-583.

(14) Tavares de Almeida (1991): 18-19. Vid. Lopes PraÇa (1879): 86-87 y Marnoco e SOUSA (1910): 474-480. 
no preguntaré si resultan acordes con la voluntad de mayorías ignorantes» (15). Pero la lógica censitaria no establecía solamente una distribución desigual del poder político, sino que sancionaba objetivamente la dominación social de las clases privilegiadas, en particular de los grupos terratenientes, y restringía drásticamente la representatividad y el alcance de la legitimidad electoral, al excluir al gran número de los no propietarios del «país legal». Como escribió Joaquim Tomás Lobo d'Ávila, «[el censo] consagra el privilegio de una clase y el expolio de otra» (16).

La tradición liberal portuguesa fue, sin embargo, relativamente benévola en el acceso al sufragio, al menos hasta 1895. La efímera legislación vintista no erigió ninguna barrera económica o educativa en el acceso a la ciudadanía activa. Y establecía elecciones directas. Porque el «resultado de la opinión pública es siempre cierto», el pueblo sólo se rebela «cuando no se le deja usar la libertad» (17); y el «sistema indirecto es el de la Santa Alianza y condena al pueblo a una perpetua minoría de edad» (18).

Si la Carta de 1826 restringió el sufragio, estrechándolo socialmente, y consagró el voto indirecto -tratando así de prevenir los riesgos de tumultos, incompetencia cívica y perversiones bonapartistas (19)-, el Acta Adicional de 1852 amplió las dimensiones del electorado, introduciendo las elecciones directas y un límite censitario uniformizado por el anterior nivel mínimo. La pacificación política resultante permitió que las elecciones pasaran a desempeñar un papel crucial como rituales de confirmación de la legitimidad de los gobernantes y como instrumento de integración social y de reclutamiento de la élite política (20).

Hasta 1878, el régimen censitario de la Carta, con un electorado que alcanzaba casi el $40 \%$ de la población masculina adulta, era comparativamente moderado. La reforma electoral de 1878 extendió el derecho al voto a todos los varones «jefes de familia» o que supiesen leer y escribir. De este modo, amplió el cuerpo electoral (que llegó a alrededor del 70\% de la población masculina adulta), incluyendo por primera vez en la ciudadanía política a grandes sectores de la población (21). Según el testimonio poco sospechoso de los republicanos, «esta ampliación del derecho de voto no es más que el sufragio universal con

(15) Carta a Oliveira Martins, 10-12-1870, in Herculano (1900): 213.

(16) LoBo D'Ávila (1848): 3.

(17) Discursos de 10 y 29-8-1821 en Fernandes Tomás (1982 [1821]): 118-119.

(18) Silva Passos (1832): 19.

(19) Tavares de Almeida (1998): ii.

(20) Tavares de Almeida (1991): 27-31 y (2010): 62. Durante el ciclo liberal, que se extiende con breves interrupciones entre 1820 y 1926 , hubo 52 elecciones generales de diputados y 28 grandes reformas electorales. Entre 1878 y el final de la monarquía constitucional en 1910, se produjeron 20 elecciones; en el mismo periodo tuvieron lugar 14 en España, 10 en Italia, 11 en los Países Bajo, 9 en Alemania y 8 en Francia.

(21) Tavares de Almeida (1991): 35 y (2015): 80. 
otro nombre» (22). Sin embargo, el sistema electoral empezó a cerrarse en 1895, con la abolición del llamado requisito social («jefe de familia»). Fue esta involución, semejante a la registrada en Italia, pero contraria a la tendencia de fondo europea que apuntaba en el sentido de la definitiva universalización del sufragio, la que distinguió la experiencia portuguesa, y no tanto los avances o retrocesos de la extensión del sufragio (23).

A pesar de la realización de elecciones directas a partir de 1852, de la introducción de distritos uninominales en 1859 y del amplio régimen de sufragio de 1878 no fue posible garantizar la celebración de elecciones libres y honestas, aunque se reconociese que de ellas dependía la verdad del sistema representativo. En vez de ser vehículos para la expresión de la voluntad popular, las elecciones servían para legitimar a los gobernantes previamente nombrados por el monarca: «los gobiernos eligen y hacen los diputados, estos por su parte apoyan a los gobiernos, como garantía de su propia conservación y origen de las mejores conveniencias» (24). Para fabricar el triunfo electoral, los gobiernos empleaban el «arsenal administrativo del Estado», recurriendo al fraude, al chantaje y hasta a la coacción de las autoridades. Los gobernadores civiles, los administradores municipales, los regidores de parroquia, los escribanos de Hacienda y los cabos de policía eran «las resortes reales, las grandes máquinas de guerra» usadas por los gobiernos para vencer en las elecciones (25).

La universalización del sufragio vino a constituir una contrapropuesta al liberalismo oligárquico y censitario. Defendida en escritos doctrinales y en panfletos (26), en manifiestos políticos (27) y en proposiciones al Parlamento (28), esta reivindicación experimentó un claro declive durante la vigencia de la generosa ley electoral de 1878 (29) y recobró intensidad tras la restrictiva reforma de 1895. A partir de entonces, el Partido Republicano encabezó el combate por el sufragio universal. No obstante, esta meta no fue alcanzada. Por otra parte, por sí sola no encerraba la garantía de la institucionalización de un

(22) Según el periódico republicano Democracia, 12-5-1878.

(23) Otra particularidad portuguesa era el enorme desnivel entre los requisitos de electores y elegibles. Tras la generosa ley de 1878, únicamente reunían los requisitos de elegibilidad un $7 \%$ de la población masculina adulta. Vid. TAVARES DE AlMEIDA (2015): 87-89.

(24) FusCHINI (1899): 345.

(25) Conde de Rio Maior, Diário da Câmara dos Pares, 15-4-1878. Vid. Tavares DE ALMEIDA (1991): 21 y (2015): 99-100.

(26) Por ejemplo, Lobo d’Ávila (1848), Consiglieri Pedroso (1876) o Henriques NoGUEIRA (1851): 20-23.

(27) Como el del Centro Republicano Federal de Lisboa, en 1873.

(28) Véase el Projecto de Lei para a Reforma da Carta Constitucional...pelos Deputados do Partido Reformista, en 1871, el proyecto del diputado histórico José Luciano de Castro em 1872 (DCD, 24-1-1872) o el del diputado republicano João Meneses en 1909 (DCD, 3-9-1909).

(29) «As classes operárias conquistaram o direito de votar, que é a carta de cidadão», $D e$ mocracia, 9-10-1878. 
régimen democrático: recuérdese el caso español, pues en este país el sufragio universal masculino entró en vigor en 1890 y a pesar de ello, hasta el final de la monarquía constitucional, la distancia entre las instituciones políticas y la sociedad, entre el «país legal» y el «país real»-tal como observa Romanelli sobre el régimen del sufragio restringido en Italia (30)- inhibió los procesos de acceso de las masas a la vida política, hipotecó la legitimidad de la monarquía constitucional y desencadenó la proliferación de propuestas nuevas, entre ellas las del conservadurismo orgánico y del republicanismo.

\subsection{Alternativas críticas: el neo-corporativismo orgánico y el republicanismo cívico}

El liberalismo buscó la transformación de las sociedades del Antiguo Régimen compuestas por comunidades urbanas y rurales distribuidas de forma segmentada por el territorio, poseedoras de identidades antiguas y arraigadas; sociedades fundadas en las diferencias de status, en las que las relaciones jerárquicas se apoyaban en mecanismos de deferencia y patronazgo. La mayoría aplastante de la población era rural, pobre y analfabeta.

El sufragio liberal no contemplaba reflejar las fracturas internas de esta realidad social sino ocultarlas bajo un manto de igualdad e individualismo. Por ser en sí mismo un «utopismo radical», prescriptivo y normativo, trataba de imponer un modelo nuevo de relaciones sociales: el de la nación hecha de ciudadanos singulares, iguales en derechos y deberes, en relación directa con la soberanía (31). Fue en la brecha entre la comunidad imaginada liberal (32) y la realidad situada de los individuos donde volvieron a emerger las ideas de representación orgánica.

Las alternativas conservadoras orgánicas no pretendían restaurar el Antiguo Régimen estamental (33). Trataban por el contrario de resolver problemas sociales y políticos contemporáneos, entre ellos sin duda la cuestión social. Tras de ellas se presentaba la denuncia del individuo aislado, considerado un artificio inexistente y peligroso. Lo que existían eran individuos atrapados en relaciones sociales: familia, comunidad, profesión, religión -entes orgánicos que en sus diferentes intereses y funciones requerían representación política armónica en el Estado-.

(30) RomANELLI (1995); 157-161.

(31) RoMANELLI (2010): 293-294.

(32) ANDERSON (2005 [1983]): 67-112.

(33) Dejemos de lado el pensamiento político contrarrevolucionario legitimista, derrotado como proyecto global en 1834, y que tuvo como principales exponentes a Acúrsio das Neves, A. J. Gouveia Pinto, António Ribeiro Saraiva o José da Gama e Castro. 
En lo tocante al sufragio, Oliveira Martins ofrece en As Eleições (1878) una crítica elocuente, resuelta en una propuesta neo-orgánica de representación (34). La «elección en su brutalidad numérica es un proceso errado. Si el resultado aritmético no está subordinado a la suerte, lo está ciertamente su resultado moral» (35). Restaba organizar la democracia, tornar «real y positiva la autoridad del pueblo» y «verdadera la representación social» (36). Esta debía ser representación de funciones e intereses orgánicos; no del individuo abstracto y sí del ciudadano en «su realidad social, esto es, las clases, y a su lado las instituciones y el medio ambiente físico y moral» (37). La representación nacional solo sería verdadera cuando, tras desterrar «las abstracciones geográficas y aritméticas [...] se busque en la representación de los órganos de la sociedad el principio constitucional de sus asambleas» (38). Por ello, propuso un «esquema de la composición de la representación social» de una Cámara legislativa integrada por 180 diputados que representasen a las «clases o profesiones, base económica de la sociedad» - 115, a las «escuelas e instituciones, base intelectual y administrativa» $-30-\mathrm{y}$ a las «regiones, base natural y geográfica» $-35-(39)$.

La reforma electoral de 1895 vino a hacer aflorar institucionalmente esta concepción. Se consideraba que en el parlamento sobraban funcionarios públicos y faltaba representación de las «fuerzas vivas» de la nación, propietarios, productores y contribuyentes. Por esta razón la ley impuso cuotas máximas para ciertas categorías: 40 para funcionarios públicos y 20 para médicos y abogados (sobre un total de 120 diputados). También en el campo socialista tales ideas fueron conquistando posiciones. Por ejemplo, en la carta que escribió a la comisión central del Partido Socialista en 1880, Antero de Quental propuso «la representación nacional por clases y funciones sociales, única manera de hacer legítima y sincera la representación y efectivos los derechos de los trabajadores» (40). Un buen indicador de la entrada de estas ideas en el tronco central del pensamiento político y académico (41) fue su inclusión en las lecciones de derecho constitucional de Marnoco e Sousa, en las que se evaluaban

(34) Oliveira Martins (1957 [1878]): 275-331. Crítica retomada en OliveiRa Martins (1885): 44-53, 63-70; Vid. CATROGA (1981): 340-520, Y HeSPANHA (2010): 127-131.

(35) OliveiRa Martins (1957 [1878]): 281.

(36) Oliveira Martins (1957 [1878]): 299-300.

(37) OliveiRa Martins (1957 [1878]): 318.

(38) Oliveira Martins (1885): 64.

(39) Oliveira Martins (1957 [1878]): 323-331; Vid. Catroga (1981): 378-368.

(40) Cit. In MónICA (1984): 89.

(41) Siempre hubo contrapropuestas orgánicas a la concepción liberal individualista en los debates públicos, por más que se situaran en una posición periférica. Por ejemplo, el jurista Silvestre Pinheiro Ferreira imaginó un sufragio orgánico en el que el status del mérito sustituyese a la criba plutocrática, con la organización de la sociedad en tres «Estados» (propiedad territorial, industria y servicios públicos), repartidos a su vez en doce «clases» correspondientes a los sectores principales de actividad (agricultura, minas, etc.), dentro de las cuales existirían «secciones», lo que implicaba una matrícula general de los ciudadanos, exámenes periódicos para comprobar la capacidad dentro de cada orden y cambios de posición. Véase PINHEIRO FERREIRA 
las formas de representar los intereses sociales en Europa y se defendía que la «representación política de la sociedad debe ser la imagen fiel de la sociedad, [...] reflejar los diversos aspectos por los que se manifiesta la actividad social. Por eso la representación de los intereses sociales es la mejor forma de la representación política» (42).

El pensamiento político católico, al dejar atrás la reacción ultramontana con León XIII, recuperó la capacidad de presentarse como una opción crítica frente a los excesos del individualismo y del capitalismo, al mismo tiempo que utilizaba las garantías cívicas y políticas liberales para agrandes su influencia, por medio de mutualidades, centros académicos, círculos obreros, sindicatos católicos y hasta partidos confesionales. Se pone de manifiesto en la política de ralliement en Francia (encíclica Au milieu des sollicitudes, de 1891) o en el levantamiento en 1904 del non expedit en Italia. En Portugal, ese viraje quedó marcado por el discurso del Obispo de Coímbra en la Cámara de los Pares, en 1894 , en el que se reconocía que la «clase eclesiástica» había errado al «meterse en el terreno de las refriegas partidistas», y apelaba a la «completa y satisfactoria armonía» entre Estado y religión (43). Desde el punto de vista de la representación, la encíclica Rerum Novarum (1891) apuntaba ya para el futuro horizonte corporativo, al prefigurar la atenuación de la tensión entre el capital y el trabajo merced a la representación orgánica y armónica de los intereses en términos de deberes mutuos.

Desde que el liberalismo dio forma estable a una vía moderada, a mediados de siglo, el republicanismo surgió como una «tercera vía» entre la «situación», el individualismo extremo y las otras vías revolucionarias, orgánicas o socialistas. El republicanismo imaginaba una sociedad compuesta por «semejantes, libres e iguales». En la fabricación de esta comunidad cívica, la educación era estratégica pues inculcaba las normas y los sentimientos de la solidaridad y pertenencia. La representación real dependería de crear en todos «un espíritu republicano, solidario y garante de iguales oportunidades para todos» (44). La escuela laica, moral, cívica y patriótica está en el centro de la «demopedia republicana» (45).

Un precursor del socialismo y del republicanismo en Portugal, Henriques Nogueira, fue bastante claro. En Estudos sobre a Reforma em Portugal, de 1851, consideraba que el origen del poder reside en el pueblo, ese «complejo

(1831): 43-110; (1832): 33-37 y (1838): 17ss, 29ss. Véase, también, EsteVes Pereira (1974) y HESPANHA (2010): 121-122.

(42) Marnoco e Sousa (1910): 164 cit in Hespanha (2010): 131.

(43) Cit. in BRAGA DA CRUZ (1980): 268. Esta aparente armonía no impidió, a partir de 1901, la tentativa de creación de una red de centros y asociaciones que se pudiesen constituir como partido católico, que finalmente pasó a existir en 1903, con la denominación de Partido Nacionalista.

(44) Hespanha (2010): 133-134

(45) Catroga (2000): 235-276. 
de todas las clases de la sociedad», y que el modo adecuado para que expresase su soberanía radicaba en que ejerciese el «incontestable derecho de gobernarse» por medio de la elección, que solo sería «perfecta cuando la universalidad de los ciudadanos fuesen llamados a votar». Por consiguiente, el voto debía ser universal, libre, directo y obligatorio, aunque también ilustrado (puesto que «nadie escoge sin saber cómo y a quién tiene que escoger»), público (para evitar «traiciones y cobardías») y legítimo («otorgado únicamente por aquellos a los que llama la ley») (46).

El programa del Centro Federal de Lisboa, de 1873, llevaba el principio de la soberanía popular a sus últimas consecuencias. Conectando las cuestiones de la forma del Estado, del régimen y del sufragio, reivindicaba la instauración de la «República Democrática Federal Portuguesa», por medio del sufragio universal para hombre y mujeres mayores de 18 años y por medio de la descentralización municipalista (47). Al campo de los federalistas se oponía el grupo de los democráticos, cuyo programa político unitarista, de 1873, apenas se distinguía del primero en lo relativo al sufragio, pues abogaba por la «igualdad cívica y política» y el «gobierno del pueblo por el pueblo» (48). Finalmente, el programa oficial del Partido Republicano Portugués, de 1891, al igual que el proyecto de reforma del sistema electoral presentado al parlamento en 1909, consagraban el sufragio universal (49). Sin embargo, y sacrificando las promesas anteriores a una lógica política instrumental, la I República (1910-1926) acabó por introducir un sufragio universal restringido, sesgado hacia las capacidades (50). El sueño de una vasta comunidad política de ciudadanos libres y capaces se siguió situando en un horizonte de futuro.

\section{EL ESTADO Y EL TERRITORIO: ENTRE LA CENTRALIZACIÓN Y LA NEGOCIACIÓN}

En Portugal, durante el siglo XIX, la organización administrativa del Estado, la articulación entre las instituciones del centro y las de la periferia y la división del territorio fueron temas recurrentes en la discusión política e incluso en la producción jurídica. Se trataba de crear un nuevo sistema territorial capaz de llevar a cabo las tareas propuestas en la ley, de integrar y desarrollar las libertades

(46) Henriques Nogueira (1851): 20-23. Vid. Esteves Pereira (1977): 159-178.

(47) O Rebate, 30-6-1873 cit. in CATROGA (2000): 45-47.

(48) Democracia, 12-10-1873 cit. in Catroga (2000): 49-51.

(49) Catroga (2000): 57-60, 175-177.

(50) La ley de 3-7-1913 limitó el sufragio a los ciudadanos varones alfabetizados, reduciendo drásticamente el universo de electores. En contrapartida, al armonizar la capacidad electoral activa y pasiva, amplió la base de reclutamiento de la élite política, que por esta razón perdió parte de su poder oligárquico y pasó a incluir segmentos de la pequeña burguesía urbana. 
locales y municipales para que sirvieran además de escuela cívica para los nuevos ciudadanos (51).

El estudio de los modelos constitucionales y de los regímenes de sufragio revela que las herencias recibidas, la agenda política y una realidad social difícil de transformar condicionaron la discusión sobre la apertura del sistema político y la universalización del derecho de voto. En esta sección intentaremos comprender cómo reorganizó el Estado liberal el territorio y afirmó su primacía sobre los poderes y las sociedades locales. El proyecto político del liberalismo buscaba centralizar la autoridad, reforzar la tutela y expropiar diversas competencias a los poderes periféricos. Como indica Catroga, este proceso de modernización, de matriz jacobino-napoleónica, consagraba «la práctica integradora de un poder político dedicado a borrar las amplias supervivencias estructurales del Antiguo Régimen, con el objetivo de instituir, institucionalizar y socializar una nueva realidad social», y se manifestaba por eso en reformas tan variopintas como la creación de contribuciones directas, la uniformización de los pesos y medidas, la división del territorio y la reorganización de sus poderes con la constitución de nuevas unidades como los distritos (similares a las provincias españolas) (52).

Esta acción pretendía constituir un sistema territorial apto a realizar nuevas funciones, acelerar el desarrollo, garantizar la división de poderes y los derechos de los ciudadanos y construir en todo el espacio nacional una comunidad política basada en la representación. La llamada centralización integraba dimensiones programáticas y utópicas presentes en la política liberal y que venían siendo realizadas por medio de adaptaciones sucesivas a una realidad en la que tenían difícil acomodo. La construcción del Estado no se tradujo, por tanto, en un haz de procesos inexorables de centralización burocrática, expropiación de los poderes locales y creación de un poder administrativo central activo e independiente de los agentes políticos (53). Por el contrario, estos procesos estuvieron caracterizados por los ajustes a las coyunturas políticas y por permanentes negociaciones asimétricas con los medios locales.

Si hacemos una genealogía de las propuestas, vemos que todas ellas tenían una misma matriz centralizadora que en modo alguno suponía un mero calco de la legislación francesa, puesto que resultaron de largos e intensos debates en las Cortes de 1821 (54). De acuerdo con el modelo prefectural francés, cada distrito y cada municipio formaban parte de un todo y en los asuntos de administración pública, lo que convenía a un ámbito también lo era para otro. El sistema creado era en apariencia jerárquico y paternalista, pero no evitaba la interacción

(51) Una intención doble, presente tanto en los autores moderados, como en los autores del campo republicano y socialista de la generación de 1848, tales como HERCULANo (1858) y HeNRIQUES NOGUEIRA (1851), respectivamente.

(52) CAtroga (2014): 34 (las cursivas en el original).

(53) Sobre estos discursos, vid. TAVARES DE AlmeIDA (2007): 53-79.

(54) Vid. CAETANo (1968): 7-23. 
con las redes políticas presentes en los diferentes niveles territoriales ni su eventual cooptación.

Para los liberales portugueses el mundo imaginado que había que construir obligaba, así, a un refuerzo de la tutela central sobre las comunidades y las instituciones locales: por medio de la reducción del número de concejos y parroquias; de la creación de unidades administrativas mayores, dotadas de ingresos y ciudadanos aptos para el ejercicio de los cargos locales; de la formación de redes burocráticas capaces de garantizar la ejecución de las leyes y las iniciativas del Estado; por un modelo de participación cívica fundada en la idea del ciudadano activo, moderadamente acomodado, relativamente independiente de las pasiones locales y con competencias escolares suficientes para gestionar cargos administrativos que recayeran en él por elección.

\subsection{El Antiguo Régimen y la revolución}

Las sociedades del Antiguo Régimen se presentaban como plurales en términos políticos y en ellas coexistían varios polos de poderes, en ocasiones en competencia. Por más que estos poderes tuvieran que guiarse por la armonía del conjunto y por el bien común, en la práctica gestionaban intereses particulares y no se hallaban sometidos a un interés público hegemónico. Predominaba la dispersión presupuestaria, la de los circuitos de comunicación y la de las atribuciones (55). No obstante, al final del Antiguo Régimen se hallaban en funcionamiento redes de penetración de la administración central en la sociedad local, como las comarcas y los corregidores, que tenían una arquitectura institucional, canales de circulación y formas de mediación propias, consistentes en la aplicación de poderes disciplinares y reglamentarios sobre los pueblos. Estas redes actuaban especialmente en las unidades administrativas de mayores dimensiones, de modo que, por ejemplo, los municipios más poblados estaban ya, en buena medida, sometidos al gobierno de «jueces de afuera» (juizes de fora), es decir, de magistrados letrados nombrados por la Corona o por donatários (56).

Este modelo de organización tenía sus propias lógicas y dinámicas de reforma y supuso la estandarización de los pesos y medidas, la regulación de los fueros y ordenanzas locales, la modernización fiscal y la creación de impuestos uniformes, el control de los pueblos y de los movimientos poblacionales, el refuerzo de la tutela sobre las autoridades locales y sobre las formas del derecho municipal (57). En todos estos procesos resultó preciso esperar a la implantación

(55) HesPanha (1994).

(56) Nota del traductor: «donatários» era el nombre con que se designaba a los nobles y a los linajes beneficiarios de una «donación» real, figura semejante a la concesión de un señorío jurisdiccional.

(57) Nogueira da Silva (1998): 36-37. 
plena de las redes políticas y administrativas construidas después de la victoria liberal de 1834. El modelo territorial fue entonces modificado con la progresiva universalización de los mecanismos de control cuantificados, con la codificación y el almacenamiento de información, con la creación de las grandes infraestructuras de circulación y de comunicación (ferrocarriles y telégrafos) y con la supervisión de los ciudadanos por redes cada vez más especializadas de empleados del Estado.

Tanto antes como después del triunfo del liberalismo, el Estado portugués no construyó sus diversos aparatos burocráticos, rígidos y especializados, desde el centro, para forzar luego a una periferia recalcitrante, integrada por campesinos y élites provinciales a aceptar los cambios. Por el contrario, el proceso fue dinámico, mantuvo siempre niveles variados de negociación y contó con la participación de los protagonistas de las provincias. De la misma manera cabe señalar que no se produjo una dicotomía clara entre un proceso de burocratización creciente, formalizado y racional, y un nivel local de poder, caracterizado por el atraso y la patrimonialización. La construcción de un modelo de Estado burocratizado y racional no se resolvió en una lucha entre los dos polos sino en un proceso de ajustes consecutivos. Tanto la administración central como los poderes locales tenían márgenes de autonomía relativa que podían emplear en los momentos decisivos, lo que permitía procesos de negociación desigual que abrían la puerta al atraso de iniciativas locales, a maniobras dilatorias en la aplicación de los reglamentos o a la búsqueda de acuerdos. No había, en consecuencia, una oposición entre centro y periferias. El Estado tuvo que cultivar los intereses locales, aunque procurase siempre mantener y reforzar los márgenes de control gubernamental sobre las comunidades y sus redes de notables.

\subsection{El centro y las periferias}

El nuevo sistema político y administrativo liberal introdujo, por medio de sucesivas normas, un modelo centralizador, en el que toda la cadena estaba ligada y subordinada jerárquicamente y el gobierno intervenía con el nombramiento de las principales autoridades con capacidad ejecutiva y poder de intermediación en todos los niveles de poder (58). Desapareció así el sistema territorial polarizado alrededor de la Corona, de sus oficiales y de los municipios, mientras surgía otro organizado en varios niveles jerárquicos.

Los lamentos por la centralización excesiva del Estado liberal fueron uno de los temas más habituales en el debate político e intelectual decimonónico. Pero la centralización se asociaba a la fuerte tutela del Estado, a la preeminencia de sus funcionarios sobre los cargos electivos locales y a lo que se presentaba

(58) Las principales normas son de 1832, 1835, 1840-1841 y 1892. Los códigos administrativos se aprobaron en 1836, 1842, 1878, 1886, y 1895-1896. 
como limitación de las libertades municipales. No era una cuestión de reducción o concesión de competencias y ni siquiera de redistribución de la fiscalidad. Si analizamos la normativa aprobada desde 1832 en adelante, observamos que las atribuciones de las cámaras no se transformaron en exceso; las que más cambiaron fueron las competencias de los provisores y administradores municipales, así como sus funciones fiscalizadoras, al ampliarse los supuestos en que se exigía la autorización de la superioridad. Es verdad que la legislación de Mouzinho da Silveira, en 1832, retiró a los municipios atribuciones judiciales antiguas e importantes así como en la aprobación y cobranza de impuestos. Aun y así los municipios retuvieron muchísimas competencias, casi todas fiscalizadas y tuteladas por la superioridad, en ámbitos tales como la gestión de los recursos naturales, la reglamentación de las actividades económicas, la limpieza y la salud públicas y la construcción y conservación de caminos e infraestructuras locales, y siguieron teniendo la posibilidad en determinadas circunstancias de establecer impuestos locales y endeudarse.

Autores influyentes, como Alexandre Herculano, escribieron asiduamente contra esta dinámica centrípeta que, en su opinión, adormecía el espíritu público, anulaba las libertades municipales y conducía al despotismo del Estado y de sus agentes. Henriques Nogueira le lanzó la acusación de que «a fuerza de querer administrar todo, no administra nada o administra todo imperfectamente; dificulta la acción de las ruedas secundarias; ejerce una tiranía en ocasiones ridícula e injustificable; produce considerables demoras en la tramitación de los negocios urgentes y multiplica de forma extraordinaria el servicio de expedientes» (59). Sin embargo, el Estado liberal precisó crear redes de agentes, de dividir los poderes y de hacer frente a un país en el que escaseaban los ciudadanos alfabetizados y donde era fuerte la resistencia pasiva de las élites a la fiscalidad.

Tras un periodo inicial, entre 1833 y 1834 , en el que se intentó poner en marcha un sistema de prefectos adaptado, la organización administrativa adquirió su forma básica en el periodo 1835-1842. Se creó una pirámide de poder presidida por el todopoderoso ministro del Reino, al que seguían los gobernadores civiles de distrito, en un tercer nivel los administradores municipales y en la base los regidores de las parroquias, formando un conjunto que se pretendía que funcionase orgánicamente. El ministro nombraba el gobernador civil y los administradores municipales y estos designaban a los regidores (60). Al lado de estos empleados nombrados, y que eran a la vez comisarios políticos, existían varios consejos y asambleas, como las juntas generales o los consejos de distrito.

La creación de una estructura bicéfala a nivel local, a partir de 1835, con un ayuntamiento [cámara] elegido y una administración del municipio [concelho] nombrada, ofreció a los municipios portugueses un margen de maniobra más

(59) HenRiQues Nogueira (1851): 64.

(60) Catroga (2014): 231-263. 
extenso que el existente en países que aplicaron versiones más canónicas del modelo prefectoral francés (61). En Portugal era común que tanto el gobernador civil como el administrador de un municipio fuesen seleccionados entre la élite local.

La nueva configuración administrativa fue indispensable para asegurar un mayor poder y capacidad de intervención en el espacio nacional y, desde el verano de 1833, funcionó como un instrumento de consolidación del régimen. El liberalismo gradualmente suprimió municipios pequeños o incompletos (en 1836, 1853 y 1855). Si en 1832 existían más de 800, en 1898 solo quedaban 286. Los liberales fueron capaces de establecer, de este modo, municipios con una media de población superior a los de España, Francia y otros países europeos (62). No obstante, el problema de los ingresos no desapareció a causa bien de la pobreza de muchas regiones, bien de la continuidad de las políticas fiscales centralizadoras, e incluso por la resistencia de los notables al aumento de los impuestos y de otras fuentes fiscales de las entradas municipales. Por tanto se puede decir que no fueron la centralización excesiva, la inestabilidad política o las frecuentes modificaciones de la legislación los factores que encadenaron la acción de los municipios. Las haciendas locales se mantuvieron débiles y dependientes de la voluntad de élites formadas por propietarios, negociantes y clases medias opuestas a gravar las actividades en los pueblos.

A lo largo del siglo XIX, a pesar de las transformaciones, en muchos municipios los bajos ingresos y la escasez de élites fuertes impidieron que se garantizase, al menos de entrada, que el medio local tuviera un peso político importante ante las nuevas autoridades y el centro político. En los municipios siguieron faltando ciudadanos capaces de desempeñar los cargos así como vecinos dotados de recursos y capacidades para conseguir entrar en las redes de poder abiertas por los nuevos canales de representación política. En otras ocasiones, los ciudadanos más capaces, ricos y escolarizados preferían alejarse de esos cargos y ejercer su influencia indirectamente, por medio de una cadena tradicional de caciques y clientes.

La reforma de las instituciones del Estado, llevada a cabo por los sucesivos gobiernos liberales desde 1832, se basó en la modernización de sus estructuras y redes y en la mayor tutela sobre los cuerpos locales y en el refuerzo del peso de las estructuras burocráticas centrales y de los empleados públicos de designación gubernamental. Sin embargo, incluso en los periodos en los que la tutela gubernamental se dejó sentir más, las autoridades y sus empleados continuaron siendo a menudo reclutados entre los grupos oligárquicos locales, abriendo vías para la negociación desigual y hasta informal con los diferentes ramos de la Administración. Este vínculo entre gobernadores civiles, administradores municipales y sus oficiales y auxiliares, por una parte, y los medios locales, por

(61) Espinha da SiLVEIRA (1997a).

(62) EsPINHA DA SILVEIRA (org.) (1997b): 65-84. 
otra, siguió siendo fuerte hasta los comienzos del siglo Xx, sin que se asistiese a la creación de carreras, cuadros y esquemas de promoción y de circulación por el país de estos empleados del Estado. La continuidad de prácticas tales como la negociación desigual, el clientelismo y el reclutamiento de notables revela la estabilidad institucional de las redes de poder, de los modelos de financiación y de los papeles que desempeñaban los empleados de las estructuras municipales y de distrito. El polémico sueño de una sociedad libre y descentralizada, apoyado en la organización y elección de los ciudadanos educados y participativos y en instituciones locales fuertes y autónomas, a la vez cimiento y escuela de la ciudadanía, se convirtió en un proyecto pospuesto.

Aunque estuvieran subordinadas y encuadradas, las periferias no eran un sujeto pasivo de la política y de la administración estatal. El modelo centralizador no las olvidaba y precisaba de ellas para funcionar. De entrada en la organización de los procesos electorales y la reunión de los votos necesarios para la legitimación de los gobiernos, previamente designados por el rey. Al contrario de lo que ocurría en el Antiguo Régimen, las nuevas redes administrativas y los circuitos que la representación política creaba permitían un mayor acceso de las élites de las periferias a los lugares de poder en el centro. Las élites dirigentes pasaron a estar reclutas en un espectro político y social más vasto, incluida una parte de los protagonistas de las provincias, normalmente acreditados con títulos de la Universidad de Coímbra y de otros centros superiores. A cambio, este sistema ofrecía a los representantes de las periferias un papel de intermediación más fuerte y directa con el gobierno central y permitía que, dentro de ciertos márgenes formales, los espacios vacíos de poder pudiesen ser ocupados por las oligarquías locales y gestionados mediante modelos clientelares. El Ministerio de los Negocios del Reino presidía este sistema, de una forma generalmente benevolente, por más que asegurase a través de su cadena administrativa la clara hegemonía del centro.

\subsection{La creación de una administración negociada}

En las primeras décadas del liberalismo, el Estado no disponía todavía de los medios humanos y materiales para desempeñar de forma eficaz sus tareas y modernizar e integrar las periferias. Utilizar una dispendiosa maquinaria burocrática, dotada de cuerpos organizados, disciplinados y profesionalizados, estaba fuera del horizonte de posibilidades. Una de las opciones posibles era integrar las redes administrativas y de poder existentes, articularlas, superponer áreas y funciones y caminar hacia un elevado nivel de pactismo y de negociación. En ese proceso fue necesario reorganizar las unidades administrativas locales, aumentar su tamaño, tutelar de forma inequívoca los municipios, urdir redes para la determinación y recaudación de los impuestos y someter a la dirección del Estado al clero 
parroquial (63). Pese a que el margen de actuación fuese reducido, no faltaron las rupturas. El funcionamiento administrativo pasó a estar regulado por leyes generales y abstractas, desaparecieron los cargos patrimoniales, se desarrolló una jerarquía funcional de los agentes, se definió el expediente escrito como medio de comunicación exclusivo y se optó por el lenguaje jurídico como forma dominante de estructurar la interlocución entre los diversos niveles.

En el centro, las reformas realizadas en 1859 permitieron poner en marcha procesos de concurso, selección y promoción de funcionarios. Por el contrario, en los municipios y distritos se mantuvieron formas de reclutamiento de empleados que estaban lejos de guiarse por criterios técnico-racionales (64). El hecho de que se simultanearan funciones y cargos burocráticos y la posibilidad de acumular pequeños empleos no ayudaron a que estos ramos de la administración fuesen independientes. Los resultados alcanzados en algunas tareas básicas del Estado, como el reclutamiento militar, la alfabetización y el cobro de los impuestos directos, estuvieron lejos de lo esperado y llevó décadas alcanzar un funcionamiento aceptable. La reforma de los pesos y medidas refleja estas carencias, como se verá en la próxima sección.

El Leviatán liberal no era tan poderoso como para poder controlar las periferias y asegurar un mando centralizado, profesionalizado y fundado en el predominio estricto de las reglas formales. Pero al mismo tiempo el nivel local tampoco podía reproducir su autonomía anterior y pasó a estar obligado a integrarse dentro de los nuevos aparatos y jugar con las nuevas reglas. Hay que recordar que el Estado portugués no tuvo que pasar por un proceso de pacificación de sus periferias, como sucedió en Italia y en España, si bien es verdad que la mayoría de las revueltas locales durante el siglo XIX constituyeron reacciones a la modernización y tuvieron siempre una componente importante de resistencia fiscal (65). En un país con una elevada homogeneidad desde el punto de vista cultural, no parecía urgente avanzar con medidas de control elevado ni de construcción de un Estado organizado pormedio de aparatos burocráticos amplios y disciplinados, que se hallasen razonablemente separados de las realidades locales. Subcontratar y negociar era más fácil y económico y permitía llevar a cabo políticas de uniformización del espacio nacional con menores costes políticos. Las antiguas unidades administrativas, como era el caso de los municipios, estaban ahí para ayudar y para hacer frente a parte de la factura de la penetración estatal, que a su vez tenía como instrumento a los administradores municipales, dirigidos por los gobernadores civiles. Ni la centralización resultó

(63) Sobre la construcción de los aparatos periféricos de Hacienda y los impuestos: SILVEIRA E SOUSA (2007): 111-137.

(64) La provisión de vacantes por concurso fue introducido en la administración de distrito en 1878. En la municipal se demoró hasta 1892. Véase TAVARES DE AlmEIDA (1995): 264-266 y 335 .

(65) Recuérdese el ciclo de revueltas de inicios de la década de 1860 y la «Janeirinha» en 1868. Véase Justino (2016): 389-459. Para el caso italiano: DAVIS (1988). 
ser un proceso inexorable ni la negociación con el nivel local aumentó necesariamente el poder y los recursos materiales de sus instituciones.

\section{EL MERCADO LIBERAL: LA REFORMA DE LOS PESOS Y MEDIDAS}

\section{1. «Un rey, una ley, un peso y una medida»}

En materia de pesos y medidas, Francia constituyó una fuente de inspiración para toda Europa, empezando por el voluntarismo puesto de manifiesto en la fase revolucionaria y siguiendo por la prudencia del Imperio y la Restauración. La decisión en 1795 de adoptar un sistema nuevo y uniforme en todo el territorio trató de evitar que la miríada de «mundos» locales se siguiese traduciendo en otros tantos sistemas de pesos y medidas. El nuevo sistema métrico-decimal únicamente se miraría en el espejo de la nación. Como sugiere el objetivo de «un Roi, une loi, un poids et une mesure», la uniformidad metrológica se vinculaba estrechamente con la igualdad jurídica (66). Mas no se trataba solo de eso. También era decisiva para el proceso de concentración de poder en el centro gubernativo, al ser coincidente con la polity, en la fiscalidad y las finanzas públicas, en la moneda, en el catastro y el registro inmobiliario, en la navegación, la cartografía, la demografía y la ciencia (67). Por último, la estandarización y la convertibilidad de los intercambios eran la condición para la extensión de las redes comerciales y del mercado, por lo que la expansión del capitalismo fue un motor clave en el impulso de unificación de los pesos y medidas.

En Portugal, al iniciarse el proceso en 1812 y cuando se adoptó el metro en 1852 , la discusión y los objetivos de la reforma eran semejantes. Al final del Antiguo Régimen se trató de generalizar en todo el reino un sistema único de pesos y medidas. Una de las vías para hacerlo era adoptar los patrones de medida de la capital (como se hizo en España en 1801); otra recurrir al metro, aunque con nombres en portugués. El reformismo ilustrado, característico del absolutismo tardío, buscaba uniformizar y racionalizar el territorio a través de la remoción de obstáculos y la superación de los «particularismos» (68), siempre con la preocupación de minimizar las tensiones posibles: «Una reforma simple y acomodada, en la medida de lo posible, a los usos y el lenguaje del pueblo, es lo que se puede y debe hacer ahora en Portugal [...]. Por tanto, señores Jueces de Afuera, concierten, revoquen, tiren [...] cuando quieran, la picota, pero no la cambien de sitio, y mucho menos a uno desconocido para el Pueblo» (69).

(66) Respecto a los cahiers de dolèance, vid. DunCAN (1984): 21.

(67) GILLESPIE (2004): 245-249.

(68) Nogueira Da Silva (1998): 35-37.

(69) ANÓNIMO [VERDIER] (1819 [1815]): 116. 
Para el liberalismo se trataba de crear una institución para la nueva economía política. La gran variedad metrológica dificultaba el libre flujo de las actividades económicas y comerciales y, en consecuencia, la edificación de un mercado interno a escala nacional (70). En tal economía, los términos de los intercambios debían ser dignos de confianza y compartidos. Según el vintista Ferreira Borges, autor del Código Comercial de 1833:

Es necesario para conveniencia del comercio que se observe regularidad en los pesos y medidas [...] Nada existe en Portugal más irregular que sus medidas, y nada clama más inmediatamente por un trabajo que las regularice y uniforme [...] De esta incertidumbre se deriva un gran embarazo y trastorno al comercio interno, y todavía uno mucho mayor al externo (71).

La unificación de los pesos y medidas es un aspecto-como los códigos civil y comercial- de la constitución política de la economía liberal, en la que al mercado, imaginado como lugar de encuentro armónico de las voluntades individuales, le corresponde una forma de gobierno que devuelve a la sociedad civil lo esencial de la regulación (72). El sistema métrico completaba -y vino a simbolizar- la extinción del Antiguo Régimen, ilustrando la constitución mutua entre individuo y Estado y entre Estado y mercado.

\subsection{Una reforma fallida (1814-1851)}

En vísperas de la revolución de 1820 todo estaba dispuesto para la unificación de los pesos y medidas. La Comisión nombrada por la Academia de Ciencias en 1812 aconsejó la adopción del sistema métrico-decimal, aunque manteniendo los nombres tradicionales (73). En 1814, Juan VI aprobó el plan de la Academia y se iniciaron los preparativos para su aplicación. Pero entre 1815 y 1820, una discusión enfrentó a los defensores del sistema existente, que proponían únicamente la generalización de las medidas de Lisboa, y a los defensores de la reforma métrica (74); unos y otros estaban de acuerdo en mantener la nomenclatura portuguesa. En marzo de 1820 las medidas estaban listas por lo que el estallido de la Revolución interrumpió objetivamente la reforma y la retrasó (75).

Solo tras la Guerra Civil recomenzó el proceso, aunque por entonces en sede parlamentaria. En la Cámara de los Pares, Teixeira Girão presentó un proyecto en defensa del mantenimiento de las medidas, nombre y subdivisiones de

(70) Justino (1989): 194-201.

(71) FERREIRA BORGES (1856 [1839]): 261-262.

(72) Hespanha (2004): 433-437.

(73) Aviso real de 5-12-1812; SiLVA LOPES (1849): 7-9.

(74) Ver Verdier (1815), y MENDO TRIGOSO (1815) y (1820), respectivamente.

(75) Aviso real de 12-9-1814. 
la metrología nacional (76), pues había sido nombrada una comisión externa de reforma en la Cámara de Diputados, pero sin efectos. En 1840, la Cámara Alta, por iniciativa de Sá da Bandeira volvió a designar la comisión de 1834, que se pronunció a favor de la generalización de las medidas de capacidad de Lisboa (77). En 1843, los diputados nombraron una nueva comisión externa, presidida por Pinheiro Ferreira, que optó por una versión del sistema métrico modificado en la nomenclatura y en las subdivisiones (78). Esta propuesta empezó a ser discutida en 1845 (79). Llamada a pronunciarse, la comisión de los Pares no alcanzó un consenso y presentó un dictamen mayoritario y votos particulares de la minoría: la generalización de las medidas de Lisboa, con nomenclatura nacional, defendida por Sá da Bandeira; el mantenimiento de las medidas existentes, preconizada por Girão; y la adopción del metro legal francés, apoyada por Margiochi (80).

Los trabajos parlamentarios se retomaron después de la revuelta de María da Fonte (1846) y el subsiguiente conflicto de la Patuleia (1847). A comienzos de 1849 la Cámara Baja volvió a formar una comisión especial que presentó su proyecto en abril, pero las sesiones concluyeron sin su discusión (81). Con el nuevo gobierno, la discusión recomenzó en 1850. Por entonces la cautela frente a las previsibles resistencias se extendió entre los intervinientes. Pero el esquema del debate no varió. Para algunos, como Silveira Pinto y Lopes de Lima, el metro debía ser adoptado pero con los nombres portugueses tradicionales; para otros, como Fontes Pereira de Melo, había que introducir el sistema métrico-decimal tout court. La posición de Fontes es importante puesto que era el ministro de Hacienda y de Obras Públicas cuando se adoptó el metro en 1852 (82). En ese momento, la Cámara Baja votó a favor de la uniformización de las medidas, escogiendo el metro como medida de base, pero manteniendo el nombre de «vara». El proceso legislativo de la medida no llegó a su fin una vez más, en este caso porque en 1851 el golpe militar de la Regeneração destituyó al Gobierno (83).

Este largo debate parlamentario dejó legados importantes para la comprensión del reformismo liberal. En primer lugar, consolidó la noción de que la sociedad estaba compuesta por individuos que ya no se hallaban ligados por los lazos adscriptivos propios de una sociedad de órdenes. Su cohesión se fundaba

(76) Diário da Câmara dos Pares, sessão de 17-9-1834. Otro proyecto de reforma fue presentado en los Pares por Sá da Bandeira en la sesión de 15-10-1834. Vid. Girão (1833).

(77) Relatorio acerca do projecto de lei..., Lisboa, Imprensa Nacional, 1840.

(78) Diário do Governo, 11-5-1843 y 17-5-1843.

(79) Diário da Câmara dos Deputados, sesión de 20-1-1845.

(80) Diário da Câmara dos Deputados, sesiones de 7-4-1845 y 2-5-1845.

(81) Diário da Câmara dos Deputados, sesiones de 9-3-1849, 12-3-1849 y 11-4-1849.

(82) BRANCO (2005a): 157-159.

(83) Véase el debate en el Diário da Câmara dos Deputados, sesiones de febrero a mayo de 1850 . 
en la división del trabajo que crea interdependencias y hace emerger un orden moral propio. El campesino se transforma en ciudadano por medio de la enseñanza primaria que lo habilita para participar en el contrato social y por el intercambio de trabajo por salario en el mercado. Su comportamiento y sus ideas eran el receptáculo del reformismo, emanado por su parte de gobiernos que creían en la infinita perfectibilidad de las instituciones sociales, económicas y políticas.

Los políticos aprendieron la necesidad de prudencia a la hora de ponderar las opciones disponibles de reforma. No concebían el paisaje social como una tabula rasa, sin limitaciones impuestas por prácticas y tradiciones antiguas, ni se veían a sí mismos como revolucionarios. La memoria de la Revuelta de María da Fonte, en particular, recordaba que los pueblos eran propensos a la conmoción cuando se hallaban confrontados a la penetración en la escala local de un Estado que había estado distante y sólo se había mostrado de forma intermitente. Como avisó un diputado, la introducción del metro podía ser aprovechada por quienes solo querían revoluciones «para hacer renacer [...] no digo la Maria da Fonte que ya estaba muerta pero sí un Manoel do Rio que estuviera todavía por nacer» (84).

La constatación de que los hábitos mudan pero más lentamente que los principios repercutió en la forma de concebir el reformismo: de la legisferación normativa se transitó a la necesidad de movilización de varios agentes (burócratas, intelectuales, párrocos, profesores de Primaria, comerciantes). Si la modificación de la ley no llega para mudar los usos sociales, entonces las autoridades, operando una combinación virtuosa entre persuasión y coacción, deben estar disponibles para ese compromiso y para apostar por la enseñanza primaria.

\subsection{Fiat lux: la reforma de 1852}

El sistema métrico decimal fue adoptado como sistema legal de pesos y medidas en 1852 (85). Después de Francia, que lo hizo en 1795, de Bélgica, Luxemburgo y los Países Bajos, que lo hicieron en 1816, y sobre todo después de España, en 1849, Portugal fue uno de los primeros países en dar ese paso (86). Al igual que en España en la década moderada (1843-1854), esta reforma integró una combinación que incluía un nuevo cuadro jurídico, la modernización y la expansión de las redes de transporte y comunicación y nuevas instituciones bancarias y de crédito, elementos todos ellos que convergían en la creación de un nuevo orden liberal fundado en el mercado interior (87). Tal y

(84) Diário da Câmara dos Deputados, sessão de 26-2-1850.

(85) Decreto de 13-12-1852.

(86) Vid. Aznar García (1997).

(87) Justino (1989): 168-227. 
como explicó Fontes en 1852, había que modernizar un «país de pueblos que no se comunican, de habitantes que no conviven, de productos que no circulan, de manufacturas que no se transportan» (88).

Según el legislador, el cambio social no es compatible con localismos y particularismos. Había que sustituir las reliquias de la tradición por una concepción racional de la «buena sociedad» y del «buen gobierno». Los antepasados están exentos de culpa o error. En otros tiempos el comercio no había adquirido «proporciones colosales», las comunicaciones no «habían convertido en un único país» a las poblaciones más distantes. Antes los municipios ponían sus intereses y privilegios por encima de los del Estado. Guiados por prejuicios y por el espíritu de campanario levantaban «límites secundarios» dentro del territorio «de la misma nación». Hoy, el «impulso de la civilización» nivela a «todos los pueblos del mismo Reino», a los que «funde y amalgama en un cuerpo político y económicamente homogéneo» (89).

Ese era el argumento decisivo: la (nueva) nación. Los pesos y medidas uniformes traducirían «en un hecho material la unidad política da nación»:

Cuando la unidad política se establece en Portugal por la Carta y por las leyes comunes; cuando la unidad moral se perfecciona sucesivamente por simpatías siempre crecientes, $[\ldots]$ cuando la unidad literaria existe gracias a la afinidad de un idioma único, $[\ldots]$ cuando la unidad industrial se funda y robustece por los esfuerzos convergentes de la población entera; cuando el espíritu de comunicabilidad se va desarrollando en una escala progresiva y las provincias extremas del reino ansían abrazarse para confundirse, para fortalecer las relaciones de trato y la convivencia social, sería desde luego una excepción deplorable mantener la incoherencia de los actuales pesos y medidas (90).

Si el Fontismo fue el nombre portugués del capitalismo, en frase de Oliveira Martins, el sistema métrico constituyó un poderoso auxiliar de la más profunda de las transformaciones estructurales -el fomento y la modernización económica, comercial e industrial-. Este argumento se repetía una y otra vez en los dictámenes de la Repartición de Pesos y Medidas. Véase, a modo de ejemplo, uno de 1860:

[...] el mercado estará dentro de poco por todas partes. Los productos fluirán adonde haya demanda, pues la facilidad de los medios de comunicación ha aproximado las distancias. Las vías rápidas las aproximarán todavía más; de aquí el crecimiento del comercio interno, para cuya facilitación viene muy a propósito la adopción de una medida igual en todo el reino [...] Y el gran y el pequeño cultivador [...] no irá solo a los mercados al lado de su casa, sino que irá adonde le convenga, lo que sin duda ayudará a la regularidad de los precios que hasta la fecha no se daba (91).

(88) Decreto de 30-8-1852.

(89) Preámbulo del decreto de 13-12-1852.

(90) Preámbulo del decreto de 13-12-1852.

(91) TEIXEIRA SILVA (1860): 282. 
El asunto central era la fabricación de una homogenización nacional, con la quiebra de los localismos y particularismos, sobre todo del antiguo margen de autonomía de los municipios, para sustentar el ejercicio del poder soberano. La afirmación del centro frente a la periferia y frente a la sociedad, afirmación basada en el gobierno de los sujetos, de las cosas y de sus relaciones. Inseparable de esa transformación estaba otra, que desde diferentes puntos de vista la exigía: la consolidación de un espacio económico a escala nacional que facilitase las transacciones mercantiles, su legalidad, su previsibilidad, la formación de precios y la movilidad de factores productivos.

\subsection{La negociación como método del reformismo}

Si el decreto de 1852 sugiere dureza, su aplicación en la práctica puso de manifiesto la necesidad del compromiso. La Repartición de Pesos y Medidas siguió diversas líneas de acción. Desde muy temprano fue palmario el caos metrológico, gracias a los dictámenes de los inspectores enviados a los municipios para comparar las viejas y las nuevas medidas (92). Los inspectores recibieron asimismo el encargo de enseñar los rudimentos del sistema a los maestros de primaria y a los padres, para que ayudasen a inculcar el «evangelio métrico». Los informes, que reconocían la importancia de la escuela y del púlpito para la aceptación del metro, eran muy críticos con los profesores y con los padres, a los cuales acusaban de alentar las reacciones atávicas contra el reformismo ilustrado (93). Los inspectores volvieron a informar sobre la aplicación concreta del metro y del kilogramo, cuya obligatoriedad entró en vigor en 1860 y 1861. En sus páginas se nos explica que la aceptación de las unidades se logró tanto mediante la coacción y las multas, como a través de la colaboración que lograron granjearse localmente los inspectores. La dureza y el rigor se aplicaban cuando la persuasión no conseguía la aceptación de los locales (94).

No obstante, el tiempo pasaba y las resistencias se mantenían. Hubo motines y revueltas en Lisboa, en Oporto, en Setúbal, en el Algarve y en el Miño (95). A lo largo de la década de 1860, los informes de los gobernadores civiles al Ministerio del Reino seguían usando las antiguas medidas, al tiempo que sus autores lamentaban que el pueblo y el comercio no adaptasen el nuevo

(92) Dictámenes publicados en el Boletim do Ministério das Obras Públicas, Comércio e Indústria. Por todos, vid. MonTEIRo Jr. y MoYa (1857): 482-486. Vid. Branco (2007): 140-144.

(93) BRANCO (2007): 148-153.

(94) BRANCO (2005a): 257-260.

(95) «Viva a Maria Bernarda/Com o seu lenço ao pescoço/Novos direitos em baixo/Os kilogramas no poço» [Viva la María Bernarda/con su pañuelo al cuello/los nuevos derechos abajo/los kilogramos al pozo], versión del himno de María da Fonte cantado por los amotinados del Miño en 1862, vid. LENOIR (1863): 46. 
sistema (96). Por considerar impolítico el recurso a la coacción y a la fuerza de la ley, el presidente del Consejo declaró en 1863 que no deseaba que el «sistema [fuese] implantado por la fuerza en el país, sino por medio de la persuasión» (97). El Gobierno no estaba dispuesto a pagar un precio político que consideraba excesivo por el metro y por el kilo. El litro no llegó por su parte hasta 1872 . Todavía en 1877, los documentos oficiales denunciaban la utilización de las medidas antiguas (98). En España, resistencias parecidas, demoras y la necesidad de compromisos hicieron que únicamente en 1880 el sistema entrase definitivamente en vigor (99).

El sistema métrico iba contra la tradición, contra los hábitos administrativos y contra las prerrogativas fiscales de los municipios, celosos de su autonomía. Su aplicación se llevó a cabo por medio de un aparato administrativo frágil y dependiente de intermediarios, de redes clientelares y de caciques. Además de la colaboración de estos actores, la implantación del sistema dependía de la capacidad de cooperar de los niveles central, periférico y municipal de gobierno, de sus posibilidades de armonizar las voluntades de los ministerios de Obras Públicas y del Reino, para movilizar a los maestros de escuela y a los párrocos, decisivos por su influencia local, y -como aconteció en el caso del censo general a partir de 1864 (100)- de mantener una (difícil) relación de cooperación entre la Administración civil y la Iglesia.

Con el liberalismo, sobre todo después de 1851, la expansión de la burocracia dotó al Estado de una estructura capilar que podía alcanzar de forma más sistemática la escala local y la vida cotidiana de los pueblos. Prueba de ello fueron las resistencias suscitadas por los poderes periféricos, los agentes económicos y los propios pueblos, con frecuencia instrumentalizados políticamente. Las protestas campesinas no se dirigían solo contra el metro. También contra la contribución territorial, los impuestos municipales, la desamortización de los bienes de las cofradías, el reclutamiento militar o los levantamientos cartográficos (101). Si resulta incontrovertible que el Estado se expandió mediante el aumento de sus capacidades, sigue siendo necesario entender el modo de esta expansión. El ejemplo de los pesos y medidas prueba que las relaciones entre la Administración, los poderes que competían con ella y la sociedad deben ser entendidos como relaciones pactistas y de negociación (102).

(96) AA. VV. (1857-1868).

(97) El ministro de Obras Públicas (Loulé) para el Jefe de la Repartición de Pesos y Medidas, 18-9-1863, =confidencial=, MOPCI RC $-13-2 /$ AHMOP.

(98) Orden circular del MOPCI a los gobernadores civiles, 23-3-1877.

(99) Decreto de 14-2-1879. Para España, véase PuEnTE Feliz (1982): 113.

(100) BRANCO (2005b): 385-438.

(101) BRANCO (2005a): 200-202, 260-267.

(102) Ver argumentos en el mismo sentido en TAVARES DE ALMEIDA (1991) y (1995): 120121; Branco (2005a): 351-356 y (2013): 70-74; Silveira E Sousa (2007): 128-131 y (2015): 141-169; y CATROGa (2014). 


\section{CONCLUSIÓN}

Estado e individuo, centro y periferias, Estado y mercado deben ser concebidos como construcción histórica en términos de implicación mutua. Esta construcción se fundó en un método: la moderación y el compromiso bajo el signo del reformismo, que fueron alimentados por tensión permanente entre la imaginación utópica liberal -el sueño- y los ajustes impuestos por la realidad -la razón-. El imaginario que subyacía a la gobernación liberal no era una tirania de las fórmulas: en él interactuaban los principios doctrinarios, la agenda política y las prácticas de poder. Sin embargo, el horizonte utópico, la idea de perfectibilidad de las instituciones políticas, sociales y económicas -en sí mismas el núcleo de su legitimidad contra el Antiguo Régimen- no pudo ser abandonado por completo.

En el siglo XIX los Estados disponían de medios materiales y humanos de administración muy limitados para desempeñar con eficacia sus vastas y crecientes tareas. El control efectivo de la acción política y burocrática y la propia penetración territorial del Estado no correspondían a la imagen de una centralización omnipotente. A pesar de los instrumentos de coacción y de los esfuerzos de racionalización de la actividad burocrática, el ejercicio de la autoridad territorial de estos «Leviatanes de papel» se enfrentó siempre a resistencia y buscó modos de llegar a pactos y formas de negociación.

El liberalismo consistió, por tanto, en una inquietud reformista. No se trataba de simples abstracciones, sino de modelos institucionales concretos, que se fueron sucediendo al ritmo de sucesivas reformas, que partiendo de la realidad buscaban su perfeccionamiento, intentando reducir la distancia entre el país legal y el país real. Siendo así, no llama la atención que las instituciones liberales realmente creadas generasen tanto desencanto, y gradualmente, falta de legitimidad, bien fuera por su cortedad respecto a lo imaginado, en el caso de los progresistas, bien porque para los más conservadores esas instituciones hubiesen elevado, de forma indefendible, la «rebelión del individuo contra la sociedad» a una tiranía impuesta por las «exigencias y la falta de previsión de las multitudes electorales» (103).

\section{BIBLIOGRAFÍA}

AA. VV. (1857-1868). Relatórios sobre o estado da administração pública nos distritos administrativos do Continente e ilhas Adjacentes. Lisboa: Imprensa Nacional.

Anderson, B. (2005 [1983]). Imagined Communities. Reflections on the Origin and Spread of Nationalism. Londres: Verso.

(103) En la expresiva fórmula de LE BoN (1905 [1895]): 184. 
Anónimo (1840). O cerco do Porto em 1832 para 1833. Porto: Tipografia de Faria e Silva, 1840.

— [Timóteo Verdier] (1819 [1815]). Carta sobre a reforma do Peso e Medidas em Portugal, Annaes das Sciencias, das Artes e das Letras, III, 1819 [28-8-1815], 99-118.

Aznar García, J. V. (1997). La unificación de los pesos y medidas en España durante el siglo XIX. Los proyectos para la reforma y la introducción del Sistema Métrico Decimal. Valência: Universitat de Valéncia.

Bonifácio, M. de F. (2005). O século XIX português. Lisboa: Imprensa de Ciências Sociais.

Braga da Cruz, M. (1980). «Os católicos e a política no final do século XIX». Análise Social, XVI (61-62), 259-270.

Branco, R. (2005a). The Cornerstones of Modern Government. Maps, Weights and Measures and Census in Liberal Portugal (19th century) [Tesis Doctoral]. Florencia, IUE [http://run. unl. pt/handle/10362/2555]

- (2005b). Contar (com) as pessoas. O Recenseamento Geral da População de 1864. Revista de História das Ideias, 26, 385-438.

- (2007). A introdução do sistema métrico-decimal em Portugal. En P. Tavares de Almeida y R. Branco (coord.). Burocracia, Estado e Território. Portugal e Espanha, séculos XIX-XX (pp. 137-162). Lisboa: Livros Horizonte.

(2013). A Vida Política (1834-1890). En P. Tavares de Almeida (coord.). História Contemporânea de Portugal. Vol 2 - 1834-1890 A Construção Nacional (pp. 31-76). Lisboa: Fundacion Mapfre/Editora Objectiva, 2013.

Caetano, M. (1968). Os antecedentes da Reforma Administrativa de 1832 (Mouzinho da Silveira). Revista da Faculdade de Direito da Universidade de Lisboa, XXII, 7-23.

Catroga, F. (1981). O problema político em Antero de Quental. Um confronto com Oliveira Martins. Revista de História das Ideias, 3, 341-520.

- (2000). O Republicanismo em Portugal. Da formação ao 5 de Outubro. Lisboa: Editorial Notícias.

- (2010). «Em nome da Nação». En F. Catroga y P. Tavares de Almeida (coord.). Res Publica 1820-1926 (pp. 20-59). Lisboa: Assembleia da República.

- (2014). A Geografia dos Afectos Pátrios. As Reformas Político-Administrativas (Sécs. XIX-XX). Coímbra: Almedina.

Consiglieri Pedroso, Z. (1876). O sufrágio universal ou a intervenção das classes trabalhadoras no governo do país. Lisboa: Nova Livraria Internacional/Bibliotheca Republicana Democrática.

Davis, J. A. (1988). Conflict and Control. Law and Order in Nineteenth Century Italy. Londres: Palgrave Macmillan. Disponible en: http://dx. doi. org/10. 1007/978-1349-19277-9

Duncan, O. D. (1984). Notes on Social Measurement. Historical and Critical. Nueva York: Russel Sage Foundation.

Espinha da Silveira, L. (1997a). Território e Poder. Nas Origens do Estado Contemporâneo em Portugal. Cascais: Patrimonia Histórica. 
- (org.) (1997b). Poder Central, Poder Regional, Poder Local. Uma Perspectiva Histórica. Lisboa: Cosmos.

Esteves Pereira, J. (1974). Silvestre Pinheiro Ferreira. O seu pensamento político. Coímbra: Universidade de Coímbra.

- (1977). «Henriques Nogueira e a conjuntura portuguesa». Revista de História das Ideias, 1, 159-178.

Fernandes, P. J. (2012). «Os Actos Adicionais à Carta Constitucional de 1826». Historia Constitucional, 13, 563-583.

Fernandes Tomás, M. (1982 [1820-1821]) y J. Tengarrinha (org.). A Revolução de 1820. Lisboa: Caminho.

Ferreira Borges, J. (1856 [1839]). Diccionario juridico-commercial. Oporto: Tip. Sebastião José Pereira.

Ferreira da Costa, F. de P. (1828). Exposição genuína da Constituição portuguesa de 1826, na qual pelo seu mesmo texto se justificam, e desfazem as contradições e barbarismos que nela se contém. Lisboa: Imprensa Régia.

Fuschini, A. (1899). O Presente e o Futuro de Portugal. Lisboa: Companhia Tipográfica.

Gillespie, C. C. (2004). Science and Polity in France: the Revolutionary and Napoleonic Years. Princeton: Princeton University Press. Disponible en: http://dx. doi. org/10. 1515/9781400865314; http://dx. doi. org/10. 1515/9781400824618

Girão, Teixeira (1833). Memoria sobre os Pesos e medidas de Portugal, sua origem, antiguidade, denominação [...]. Lisboa: Imprensa Nacional.

Henriques Nogueira, J. F. (1851). Estudos sobre a Reforma em Portugal. Lisboa: Tip. Social.

Herculano, A. (1858). Carta aos Eleitores do Círculo Eleitoral de Sintra. Lisboa: Tip. do Jornal do Comércio.

- (1897 [1873]). Opúsculos, tomo I. Lisboa: Tavares Cardoso e Irmão. (1900). Cartas de A. Herculano, tomo I. Lisboa:Bertrand.

Hespanha, A. M. (1994). As Vésperas do Leviathan: Instituições e Poder Político em Portugal, século XVII. Coímbra: Almedina.

- (2004). Guiando a Mão Invisível. Direitos, Estado e Lei no Liberalismo Monárquico Português. Coímbra: Almedina.

- (2010). A representação orgânica. En F. Catroga y P. Tavares de Almeida (coord.). Res Publica 1820-1926 (pp. 112-143). Lisboa: Assembleia da República.

Justino, D. (1989). A Formação do Espaço Económico Nacional. Portugal 1810-1913, II vols. Lisboa: Vega.

- (2016). Fontismo. Liberalismo numa Sociedade Iliberal. Lisboa: Dom Quixote.

Le Bon, G. (1905 [1895]). Psychologie des foules. París: Édition Félix Alcan.

Lenoir, L. (1863). Portugal em 1862. Lisboa: Imprensa de J. G. de Sousa Neves.

Lobo d'Ávila, J. T. (1848). Verdadeira Reforma Eleitoral ou do Suffragio Universal. Lisboa: Oficina de Manuel de Jesus Coelho.

Lopes Praça, J. J. (1879). Estudos sobre a Carta Constitucional de 1826 e Acto Adicional de 1852. Coímbra: Livraria Portuguesa e Estrangeira. 
Marnoco e Sousa, J. F. (1910). Direito Político. Poderes do Estado. Sua organização segundo a ciência política e o direito constitucional português. Coímbra: França Amado.

Mendo Trigoso, S. F. (1815). Memoria sobre os pesos e medidas portuguezas, e sobre a introducção do systema metrico-decimal. Lisboa: Oficina da Academia Real das Ciências, $\mathrm{s} / \mathrm{d}$.

- (1820). Memoria sobre as Medidas Portuguezas, em resposta ao que sobre este assumpto vem escripto no $\mathrm{n}^{\circ} 4$ do Observador Lusitano, e no terceiro Volume dos Annaes das Artes. Annaes das Sciencias, das Artes e das Letras, VII, 26-49.

Mónica, M. F. (1984). O Movimento Socialista em Portugal (1875-1934). Lisboa: INCM.

Monteiro, N. (2013). A Vida Política. En J. M. Pedreira y N. G. Monteiro (coord.). História Contemporânea de Portugal. Vol 1 - 1808-1834 O Colpaso do Império e a Revolução Liberal (pp. 37-74). Lisboa: Fundacion Mapfre/Editora Objectiva, 2013.

Monteiro Jr, J. y Moya, F. (1857). Relatório dos oficiais encarregados da comparação das medidas e pesos dos concelhos de Cascais, Sintra, Mafra, Torres Vedras, Lourinhã, Cadaval, Alenquer, Azambuja e Arruda. Boletim do Ministério das Obras Públicas, Comércio e Indústria, 482-486.

Nogueira da Silva, A. C. (1998). O Modelo Espacial do Estado Moderno: reorganização territorial em Portugal nos finais do Antigo Regime. Lisboa: Editorial Estampa.

Oliveira Martins, J. P. (1957 [1878]). As Eleições em História e Política. Lisboa: Guimarães Editores, pp. 275-331.

— (1991 [1879]). História de Portugal. Lisboa: Guimarães Editores.

(1885). Política e Economia Nacional. Oporto: Magalhães e Moniz Editores.

Ordonez, J. (2008). Utopía y Distopía en el XIx Español. En Manuel Suarez-Cortina (ed.). Utopías, quimeras y desencantos. El universo utópico en la Espanã liberal (pp. 43-72). Santander: Universidad de Cantabria.

Pinheiro Ferreira, S. (1831-1832). Projectos de Ordenações para o Reino de Portugal, 1831, tomos I y III. París: Oficina Tip. de Casimir.

- (1838). Projecto de Código Político para a Nação Portuguesa. París: Rey e Gravier.

Puente Feliz, G. (1982). «El Sistema Métrico Decimal. Sua importancia e implantacion en España». Cuadernos de Historia Moderna y Contemporánea, 3, 95-125.

Romanelli, R. (1995). Il Comando Impossibile. Stato e società nell'Italia liberale. Bolonia: Il Mulino.

- (2010). Cidadania e representação política na Europa liberal. En F. Catroga y P. Tavares de Almeida (coord.). Res Publica 1820-1926 (pp. 290-303). Lisboa: Assembleia da República.

Sardica, J. M. (2012). A Carta Constitucional portuguesa de 1826. Historia Constitucional, $13,527-561$.

Silva Lopes, J. B. (1849). Memoria sobre a reforma dos pesos e medidas em Portugal segundo o systema metrico-decimal. Lisboa: Imprensa Nacional. 
Silva Passos, M. da (1832). Memorial sobre a necessidade e meios de destruir prontamente o tirano de Portugal e restabelecer o trono da senhora Dona Maria II e a Carta de 1826. París: Auguste Mie.

Silveira e Sousa, P. (2007). A construção do aparelho periférico do Ministério da Fazenda em Portugal (1832-1878). En P. Tavares de Almeida y R. Branco (coord.). Burocracia, Estado e Território. Portugal e Espanha, séculos XIX-XX (pp. 111-136). Lisboa: Livros Horizonte.

- (2015). Tutelar, negociar e dirigir: o Estado liberal, os governos civis e os poderes locais (1834-1926). En P. Tavares de Almeida y P. Silveira e Sousa (coord.). Do Reino à Administração Interna: História de um Ministério (1736-2011) (pp. 149-161). Lisboa: INCM.

Suanzes-Carpegna, J. V. (2007). El constitucionalismo español y portugués en la primera mitad del siglo XIX. Un estudio comparado. En I. Álvarez Cuartero y J. Sánchez Gómez (eds.). Visiones y revisiones de la Independencia americana. La Independencia de América, la Constitución de Cádiz y las Constituciones Iberoamericanas (pp. 13-51). Salamanca: Universidad de Salamanca.

Tavares de Almeida, P. (1991). Eleições e Caciquismo no Portugal Oitocentista. Lisboa: Difel.

— (1995). A Construção do Estado Liberal. Lisboa: FCSH-UNL. Disponible en: http://run.unl.pt/handle/10362/2345.

- (org.) (1998). Legislação eleitoral portuguesa (1820-1926). Lisboa: INCM. (2007). A burocracia do Estado no Portugal liberal (2. ${ }^{a}$ metade do século XIX). En P. Tavares de Almeida y R. Branco (coord.). Burocracia, Estado e Território. Portugal e Espanha, séculos XIX-XX (pp. 53-79). Lisboa: Livros Horizonte.

- (2010). Eleitores, voto e representantes. En F. Catroga y P. Tavares de Almeida (coord.). Res Publica 1820-1926 (pp. 60-89). Lisboa: Assembleia da República.

- (2015). Elecciones y reclutamiento parlamentario en Portugal. En J. Moreno Luzón y P. Tavares de Almeida (eds.). De las urnas al hemiciclo. Elecciones y parlamentarismo en la Península Ibérica (1875-1926) (pp. 79-113). Madrid: Marcial Pons.

Teixeira Silva, F. (1860). Relatório acerca do ensino do systema métrico no districto de Coímbra. Boletim do Ministério das Obras Públicas, Comércio e Indústria, 279292.

Verdier, T. (1815). Memoria sobre os Pesos e Medidas portuguezes comparadas com as francesas. O Observador Luzitano em Pariz, I, 516-549. 